\title{
Quality of life: what does it mean for general practice?
}

There is no doubt that maintenance or improvement of health-related or diseaserelated quality of life (QoL) is the ultimate goal of general practice. When keeping this in mind it focuses practice not only on the physical aspects of disease, but also on how patients perceive their illnesses. Defining general practice as 'comprehensive personal care"1 implies that therapies should be balanced between evidence and patient preferences, which are influenced by their present and anticipated future QoL. This is especially relevant in treating chronic and palliative patients, when shared decisions should be made about surgery, medication and pain relief, withholding of treatment, and even some forms of euthanasia.

In the last few decades many studies have examined the concept of QoL and methods to gain a clear view of this aspect of history-taking. Symptoms only partially reflect the perceived burden of the disease. Ferrans ${ }^{2}$ showed that in patients with cancer, QoL instruments provide additional information about side effects and the impact on other aspects of life that cannot be captured by measures targeted at key symptoms.

There is a considerable discrepancy between patients' assessment of their own health and their doctor's judgement. ${ }^{3,4,5,6}$ So it is vital for GPs to ask questions about the commonly distinguished QoL domains of physical, mental, social, and psychological consequences of disease. Instruments to overcome bias in the perceptions of healthcare providers might be helpful in determining QoL. The content, the phrasing, and ways of administering of the instruments is the subject of many studies validating generic or diseasespecific instruments. Generic instruments (such as the SF-36, ${ }^{7}$ EQ-5D, ${ }^{8}$ SF-6D, ${ }^{9}$ WHOQOL-100, ${ }^{10}$ Sickness Impact Profile, ${ }^{11}$ Nottingham Health Profile, ${ }^{12}$ and the COOP/WONCA ${ }^{13}$ charts) and diseasespecific instruments have to meet criteria for validity, reliability, sensitivity to change, and applicability. ${ }^{14}$

Recent reviews have emphasised the difficulties of choosing between the large number of QoL instruments available. For instance, one study on QoL instruments for children and adolescents found 30 generic and 64 disease-specific instruments. ${ }^{15}$ Great efforts have been made to cross-validate QoL instruments for various diseases, nationalities, cultures, and target populations.

Often researchers are advised to use a generic as well as a disease-specific instrument to cover all methodological criteria. But for integration in daily practice the key issue is measuring QoL in a way that provides relevant information for patients' and practitioners' decisionmaking; focuses the practitioners' attention on the patients' concerns; and is easy to administer during routine care. Major questions to ask are whether we can use these instruments in clinical practice and for (economic) decisions in the area of public health.

In the present issue of the BJGP two studies are published from the Respiratory Research Group in Manchester.16,17 Both studies are based on postal surveys carried out in the registered population of two general practices. The surveys included the EQ-5D: a generic QoL instrument covering the five dimensions of mobility, self-care, usual activities, pain/discomfort, and anxiety/depression, from which an index score is calculated. In the first study ${ }^{16}$ a cross-sectional analysis showed how comorbidity affects the EQ$5 \mathrm{D}$ index. In the second study ${ }^{17}$ the changes in the EQ-5D scores were calculated for patients who had three consecutive measurements over a 5-year period. The researchers found that $\mathrm{QoL}$ decreases with increasing numbers of chronic conditions, and that in a cohort of about 2500 participants the quality of life declined significantly over 5 years after adjusting for age, education level and duration, sex, and smoking behaviour.
Although the studies were performed 5 years ago and were locally restricted, these results may have implications for clinical practice and public health in general.

The various QoL measures can be used for research purposes, economic decision making, and for decision making in clinical practice, but need to be tailored to these goals. ${ }^{15}$

In clinical practice QoL measures are currently used for needs assessment and monitoring purposes. Chronic disease management systems, with the aim of delivering systematic multidisciplinary care that is also targeted at individual needs, often incorporate disease-specific instruments to assess needs and/or to monitor changes in perceived disease consequences.

Older patients are often included in several disease management systems because they have more than one chronic condition. They often have to complete several QoL instruments thus increasing the 'load of care' for themselves and the burden for the health professionals. The use of one generic instrument, like the EQ-5D which shows a decrease in QoL with an increase in number of diseases, may reduce this load. This presents a dilemma, as generic instruments provide less information on the perceived effects of particular conditions than diseasespecific ones, and specific instruments are more responsive to changes in disease conditions than the corresponding domains of generic instruments. ${ }^{18}$

For clinical practice, QoL measures should be easily incorporated into the daily routine. Different ways of administering tests (interview or questionnaire, by telephone or computer, the frequency and time intervals of administering) affect patient scores, as does the type of questioning. To illustrate how type of questioning can have an impact patient scores, a study on patients with HIV1 infection showed that they 
evaluated their QoL significantly worse when the questioning was retrospective compared to prospective, and that the retrospective scores showed better associations with change in clinical indicators than the prospective questioning. ${ }^{16}$

QoL instruments are also needed as outcome indicators to calculate qualityadjusted life years and cost-effectiveness of therapy and care-delivery interventions. The study by Hazell et al showed ${ }^{17}$ an autonomous decrease in QoL over a 5year period, indicating the difficulty of taking a point of reference. Questions arise around the validity of health-related QoL measures; for example, which cultural and economic influences interfere with health related QoL? These questions around validity and reliability gain prominence when QoL measurements are used as patient outcome parameters in quality assessment and pay-forperformance systems.

Although much focus is put on hard clinical outcome measures like reducing blood pressure or $\mathrm{HbA} 1 \mathrm{c}$, it is understandable that those responsible for public finances and for safe and effective health care are looking for measures related to the ultimate goal of care. But a rule of thumb should be that performance indicators are related to those aspects of care delivery that can be controlled and changed by healthcare professionals. ${ }^{19}$ It is a challenge for research and practice to find ways and instruments to base quality assessments on how patients evaluate their quality of life related to the care that they received.

A key issue for general practice is taking into account patients' needs and preferences and the context of the patient. Health professionals' views often differ from patients' perceptions. GPs differ in their routine questioning. The systematic incorporation of QoL measures in consultations may be helpful to get a clearer picture of how patients perceive their health-related QoL and its course.

QoL measures can also be helpful as a stimulus for practice improvement when used as patient outcomes in quality assessment procedures. The use of QoL measures as indicators in pay-forperformance systems is unlikely in the near future; still, it is a challenge for research and clinical practice to find ways to increase patient centredness by using QoL instruments in general practice.

\section{JE Jacobs,}

Senior Researcher, Department of IQ

Healthcare, Radboud University Medical Centre Nijmegen, The Netherlands.

\section{Provenance}

Commissioned; not peer reviewed.

\section{REFERENCES}

1. Martin JC, Avant RF, Bowman MA, et al. The Future of Family Medicine: a collaborative project of the family medicine community. Ann Fam Med 2004; 2(Suppl 2): S3-32.

2. Ferrans CE. Differences in what quality-of-life instruments measure. J Natl Cancer Inst Monogr 2007; (37): 22-26.

3. Undén A, Elofsson S. Health from the patient's point of view. How does it relate to the physician's judgement? Fam Pract 2001; 18(2): 174-180.

4. Ewing G, Rogers M, Barclay S, et al. Palliative care in primary care: a study to determine whether patients and professionals agree on symptoms. Br J Gen Pract 2006; 56(522): 27-34.

5. Sprangers MA, Aaronson NK. The role of health care providers and significant others in evaluating the quality of life of patients with chronic disease: a review. J Clin Epidemiol 1992; 45(7): 743-760.

6. Grande GE, Barclay SI, Todd CJ. Difficulty of symptom control and general practitioners' knowledge of patients' symptoms. Palliat Med 1997; 11(5): 399-406.

7. Ware JE Jr, Sherbourne CD. The MOS 36-item shortform health survey (SF-36). I. Conceptual framework and item selection. Med Care 1992; 30(6): 473-483.

8. The EuroQol Group. EuroQoL — a new facility for the measurement of health-related quality of life. The EuroQol Group. Health Policy 1990; 16(3): 199-208.

9. Brazier J, Usherwood T, Harper R, Thomas K. Deriving a preference-based single index from the UK SF-36 Health Survey. J Clin Epidemiol 1998; 51(11): 1115-1128.

10. The World Health Organization Quality of Life Assessment (WHOQOL): development and general psychometric properties. Soc Sci Med 1998; 46(12): 1569-1585.

11. Bergner M, Bobbitt RA, Kressel S, et al. The sickness impact profile: conceptual formulation and methodology for the development of a health status measure. Int J Health Serv 1976; 6(3): 393-415.

12. Hunt SM, McEwen J, McKenna SP. Measuring health status: a new tool for clinicians and epidemiologists. J R Coll Gen Pract 1985; 35(273): 185-188.

13. Nelson EC, Landgraf JM, Hays RD. The COOP function charts: a system to measure patient function in physicians' offices. In: Lipkin M (ed.). Functional status measurement in primary care. New York: Springer-Verlag, 1990

14. Guyatt GH, Kirshner B, Jaeschke R. Measuring health status: what are the necessary measurement properties? J Clin Epidemiol 1992; 45(12): 1341-1345.

15. Solans M, Pane S. Estrada MD, et al. Health-related quality of life measurement in children and adolescents: a systematic review of generic and disease-specific instruments. Value Health 2008; 11(4): 742-764.

16. Heyworth ITM, Hazell ML, Linehan MF, Frank TL How do common chronic conditions affect healthrelated quality of life? Br J Gen Pract 2009; 59(568): 833-838.

17. Hazell ML, Morris JA, Linehan MF, Frank. TL. Temporal change in health-related quality of life: a longitudinal study in general practice 1999-2004. Br J Gen Pract 2009; 59(568): 839-843.

18. Wiebe S, Guyatt G, Weaver B, et al. Comparative responsiveness of generic and specific quality-of-life instruments. J Clin Epidemiol 2003; 56(1): 52-60.

19. Giuffrida A, Gravelle H, Roland M. Measuring quality of care with routine data: avoiding confusion between performance indicators and health outcomes. BMJ 1999; 319(7202): 94-98.

20. Deyo RA, Patrick DL. Barriers to the use of health status measures in clinical investigation, patient care, and policy research. Med Care 1989; 27(3 Suppl): S254-S268.

21. Nieuwkerk PT, Tollenaar MS, Oort FJ, Sprangers MA. Are retrospective measures of change in quality of life more valid than prospective measures? Med Care 2007; 45(3): 199-205.

DOI: 10.3399/bjgp09X472854

\section{ADDRESS FOR CORRESPONDENCE}

\section{JE Jacobs}

Radboud University Medical Centre, 114 IQ Healthcare, PO Box 9101 , 6500 HB Nijmegen, The Netherlands. E-mail: J.Jacobs@iq.umcn.nl 